\title{
Good looks and good practice: the attitudes of career practitioners to attractiveness and appearance
}

Julia Yates

Tristram Hooley

Kiren Bagri Kaur

\begin{abstract}
Empirical evidence attests the impact that career image has on objective career success, yet little is known of how career practitioners conceptualise and operationalise this information. This article presents the quantitative findings of an online survey of career practitioners ( $n=399,74 \%$ female, 89\% white, 75\% from the UK) exploring their attitudes and practices towards issues of appearance and attractiveness. Career practitioners who participated in this survey acknowledged that beauty, self-presentation and interpersonal skills influence career success, and $96 \%$ of them considered conversations about career image as part of their professional remit. The career practitioners felt relatively comfortable and well informed in their discussions in this arena, but would welcome further guidance and training to inform their practice. Ethical and practical implications for the profession are considered.
\end{abstract}

Keywords career guidance, career image, appearance, attractiveness, career practice

\section{Career image and career success}

Good looking, well-dressed and charming people have a distinct advantage in the workplace. Although some may find this disconcerting, the evidence is clear and consistent, and the impact that appearance has on objective career success throughout the working life has been widely documented (see Hooley \& Yates, 2015 for a review).

There is a wealth of research from the perspective of both the individual and the organisation examining the different aspects of appearance and the different ways that particular features may influence career paths. Hooley and Yates (2015) have coined the term 'career image' as a conceptualisation of the phenomenon, broken down into three elements: beauty (basic good looks), self-presentation (clothing and image appropriate for the particular industry) and interpersonal skills (the ability to develop relationships). There is a limited empirical evidence basis for this construct but an extensive literature demonstrates that each of the three elements has a significant bearing on career success.

Aspects of beauty which have been shown to have an impact in the workplace include a beautiful face, which was shown in a field experiment in Argentina to lead to a higher number of job interviews (Bóo, Rossi \& Urzua, 2013) and a good figure (Agerstrom \& Rooth, 2011, for example, demonstrated a negative correlation between obesity and invitations to job interviews in a largescale field experiment in Sweden). Issues of self-presentation which have been shown to influence career include dress (Karl, Hall \& Peluchette, 2013, for example, found that particular styles of clothing were linked with personality traits for city employees in Australia), and adornments such as tattoos have been shown in experimental studies to be linked with negative personality traits 
(Resenhoft, Villa \& Wiesman, 2008). Significant interpersonal skills that have been shown to be important include handshakes (Stewart, Dustin, Barrick \& Darnold, 2008, for example, found that a firm handshake was linked to positive hiring decisions, particularly for female applicants) and accents which Eustace (2012) demonstrated had an impact on both the career choice and interview success of unemployed Glaswegians considering frontline customer service roles. Eye contact has been shown to make job applicants appear to be more competent and more hireable (for example, Burkhardt, Weider-Hatfield \& Hocking's 1985 study on summer reception jobs) and the ability to make conversation was found to be one of the key predictors of employment interview success in a meta-analysis (Huffcutt, Conway, Roth \& Stone, 2001).

Career success is determined by a range of factors (Ng, Eby, Sorensen \& Feldman, 2005) but imagerelated features have been shown to influence a wide range of aspects of objective career success, ranging from the chances of getting an invitation to a job interview (Agerstrom and Rooth, 2011), through to salary (Judge \& Cable, 2011). The evidence demonstrates too that the impact of career image spans right across the working life (Jaeger, 2011). Other research has shown that individuals often struggle to understand fully and respond to the social rules that govern good 'career image'. Cutts, Hooley and Yates (2015), for example, explored the aesthetic challenges which UK graduates face as they negotiate the identity transition from undergraduate to employee.

Some of the research has considered this phenomenon as an equality issue, often using the language of 'lookism' (Cavico, Muffler \& Mujtaba, 2012). A culture which confers advantages on the beautiful and charming serves to compound the barriers facing a number of groups who are already disadvantaged in the workplace. These groups include older workers, those with disabilities and those from lower socio-economic groups (Berger, 2009; Madera \& Hebi, 2012).

Issues of attractiveness and appearance have been theorised by Hakim (2010) in her concept of erotic capital. This concept has been contested by those such as Green (2013) who noted that it divorces the advantages a good image can bring from Bourdieu's concepts of social, cultural and financial capital (Bourdieu, 1985 and 1993). In contrast the literature around aesthetic labour (Hall \& van den Broek, 2012; Sheane, 2012; Warhurst \& Nickson, 2007) situates these issues of appearance, attractiveness and charm squarely within broader power relations, viewing them as at least in part a manifestation of social, cultural and financial capital.

\section{Career image and career practice}

The evidence for the importance of career image raises some important questions for career practitioners. Is this something to be engaged with or avoided? Should career practitioners encourage individuals to enhance their career image or should they be raising questions about issues of power and discrimination inherent in the social value accorded to attractiveness? The nature of career practitioners' engagement with career image clearly proceeds from a broader question about the position of career workers more generally. A detailed examination of this is beyond the scope of this paper, but it is important to recognise that career work proceeds from a range of ontological positions (mapped by Watts, 1996) and epistemologies often related to various disciplines including psychology, education and sociology. These positions in turn suggest different approaches to interventions that further shape the way career practitioners address career image. For the purpose of this research we have taken a broad and multi-disciplinary definition of career work. Career practitioners here include career counsellors, career coaches, career educators and other kinds of career workers. Individuals who responded to the survey self-identified as career practitioners, and the nature of the role, the context within which the work is done and the level of qualifications of 
practitioners were not pre-determined or ascertained through the questionnaire. As a result, the career work reported is likely to include both one-to-one and group practice, and we recognise that individual career practitioners may approach questions about career image from different professional perspectives.

Hooley and Yates (2015) have explored how these issues might be addressed by career practitioners, arguing that given the clarity of the research on this issue, it is a topic which should not be ignored. They highlight tensions relating to professional ethics (balancing the needs of the individual client with a responsibility to enhance social justice in the workplace) and professional competence (whether practitioners have the requisite skills and expertise to fulfil this role).

Developing a clear understanding of the appearance and behaviour which will bring career success is no mean feat. Explicit dress codes tend to cover only extreme examples of inappropriate attire 'no spaghetti straps' or broad requirements 'business casual' (Hazen \& Syrdhal, 2010); the nuances of how smart, how fashionable and how homogenous the right 'look' may be tend not to be written down. Bourdieu's notion of 'habitus' (1993) is one which can help explain the challenge of providing image advice to clients. Habitus refers to the set of implicit codes which govern all aspects of behaviour (including what to wear, and how to look) within a specific social context, such as a workplace. These unspoken rules are difficult to pin down or articulate for those not intimately familiar with the field (Ustuner \& Thompson, 2012).

These issues are clearly important for career practitioners, however Hooley and Yates's article (2015) only addresses these issues conceptually and culminates in a recognition of the empirical gap that exists in this area. Existing literature provides clear evidence that appearance influences career trajectories, but no indication of whether career practitioners are aware of, or acknowledge this impact and no information about the way that professionals respond to these issues in their professional practice. An understanding of current practices in this arena would provide a starting point from which to develop a wider consensus of an appropriate professional response to the topic and guidelines for practice which is both effective and ethical. It is this gap, therefore, that the current empirical study addresses, providing initial data on the views, reactions and practices of career professionals in this arena.

There is no pre-existing research which has examined the attitudes of career practitioners to career image. A series of exploratory hypotheses were therefore developed based on the knowledge gleaned during discussions about this topic with career practitioners. These were as follows.

H1: Career practitioners believe that career image is important to objective career success.

H2: Career practitioners discuss career image with their clients.

H3: Career practitioners are more likely to have discussions about the elements of career image which they believe have most impact on career success.

H4: Career practitioners' levels of comfort in these discussions are associated with a range of factors including demographic features and their beliefs about career image.

As there is no prior empirical literature on careers practitioners and career image, this study needs to be understood as an exploratory one. The findings of this study should therefore be interpreted as part of a process of exploratory data analysis or 'rough confirmatory analysis' (Behrens, 1997). As such the ambition of this paper is not to establish conclusive models, but rather to provide an empirical basis from which further hypotheses can be developed. 


\section{Methodology}

An online survey was developed which could be widely distributed throughout the sector. We drew on key methodological thinking in relation to online surveys in the design, recruitment and analysis of this survey (e.g. Couper, 2008; Evans \& Mathur, 2005; Hooley, Marriott \& Wellens, 2012). The survey was designed in Survey Monkey with 39 questions exploring career professionals' attitudes and practices relating to career image. ${ }^{1}$ Questions included: 'Would you raise issues of appearance with clients?'; 'How well informed do you feel about the different clothing/appearance different employers are looking for'; 'How comfortable do you feel giving advice or feedback on these issues with clients?'; and 'To what extent do you feel the following factors are important to career success (factors included eye contact, handshake, ability to make conversation, an attractive face, appropriate clothing, avoiding inappropriate tattoos)?'. The questions were based on evidence from the literature (for example, the factors in this last example are all shown within the literature to have an impact on career success, e.g. Huffcutt et al., 2013, Stewart et al., 2008). Qualitative comments from the career practitioners who completed the survey indicated that the list did not paint a full picture of the topics discussed within career conversations. Future research may usefully incorporate a larger number of factors, including personal hygiene.

Whilst a questionnaire was considered a useful medium for gathering data from a large number of participants across the UK and beyond, it should be acknowledged that the topic of career image is potentially a sensitive one and the data gathered could be biased by issues such as social desirability or practitioner confidence.

Questions explored the demographics of the career practitioners who responded including their selfassessment of their own career image. The majority of questions were pre-coded multiple choice or multiple answer questions although the option to write in an "other" response was frequently offered generating qualitative data which had to be post-coded. This article concentrates on the analysis of the quantitative data gathered through this survey. A subsequent article will address the qualitative information.

Following the design of the survey, an ethics form was submitted and approved by a university ethics committee. It was recognised that some career practitioners may feel that this study addressed a number of sensitive issues, but the voluntary and anonymous nature of the survey, and the professional nature of both the topic and participants meant that the ethical risks of the project were judged as minimal.

\section{Participants}

An inclusive approach to recruitment was taken. An opportunity sample was considered particularly appropriate because (1) the research was designed to be broad and exploratory and (2) the limited demographic information available about career practitioners would make stratified sampling difficult. As a consequence the survey was targeted at all those who self-defined as career practitioners. While focused on the UK, provision was made in the survey to accommodate international practitioners.

Recruitment took place over January and February 2015 and extensive use was made of online gatekeepers. Murray and Sixsmith (1998) have argued that the involvement of such gatekeepers is essential for ensuring engagement in online research. The researchers used their own networks,

\footnotetext{
${ }^{1}$ The survey instrument is deposited as an associated file on the journal website.
} 
blogs and websites as well a wide range of websites, social media and email lists maintained by professional associations, organisations, prominent individuals and other kinds of gatekeepers. In addition, research was undertaken online to identify the managers of large careers services and employers of careers advisers who were asked to circulate the survey to their staff.

The use of a large opportunity sample was useful given the exploratory nature of this research; however there are a number of associated limitations. This approach to recruitment is unlikely to have generated a representative sample of practitioners from the profession, and the self-selecting nature of the participants means that the sample is likely to be skewed towards practitioners who have an interest in this area. Whilst some demographic data were gathered, the nature of this convenience sampling inevitably means that limited information was gleaned about the specific practices of the career practitioners who participated in the survey, and this should be factored in whilst interpreting the results. Future researchers may wish to consider whether it is possible to gather a more statistically representative sample of the population or to focus exploration on a subpopulation (e.g. careers advisers in schools) which is easier to define.

The survey received 477 responses. The data were cleaned by deleting subjects with missing data for the key variables. This resulted in a cleaned dataset of 399 career practitioners. Table 1 presents demographic information about the career practitioners who responded to the survey, and Table 2 presents professional information about the career practitioners who responded to the survey.

\section{Table 1 Demographic Information}

[Table 1 near here]

[Table 2 near here]

Table 2 Professional Information

\section{Analytical Procedures}

Descriptive statistics were used to identify means and standard deviations in order to test the hypotheses $\mathrm{H} 1$ (Career practitioners believe that career image is important to objective career success), H2 (Career practitioners discuss career image with their clients) and H3 (Career practitioners are more likely to have discussions about the elements of career image which they believe have most impact on career success). The fourth hypothesis (Career practitioners' levels of comfort in these discussions are associated with a range of factors including demographic factors and their beliefs about career image) was tested with two multiple regression models, one exploring the associations between levels of comfort and demographic factors, and the other exploring the associations between levels of comfort and career practitioner beliefs.

Preliminary analyses were conducted to ensure no violation of the assumptions of normality, independent errors, linearity, multicollinearity and homoscedasticity. Tests to see if the data met the assumption of collinearity indicated that multicollinearity was not a concern (tolerance scores ranged from .230 to .911 and the Variance Inflation Factor [VIF] ranged from 1.1 to 4.4). The data met the assumption of independent errors (Durbin-Watson value $=1.872$ for the demographic factors model and 1.892 for the beliefs model). The histogram of standardised residuals indicated 
that the data contained approximately normally distributed errors as did the normal P-P plots of standardised residuals which showed points that were not completely on the line but were close. The scatterplot of standardised predicted values showed that the data met the assumptions of homogeneity of variance and linearity.

\section{Results}

The analysis of the quantitative data revealed that two hypotheses $(\mathrm{H} 1$ and $\mathrm{H} 2)$ were supported. $\mathrm{H} 3$ and $\mathrm{H} 4$ were partially supported.

\section{Career practitioners believe that career image is important to career success.}

H1 (Career practitioners believe that career image is important to objective career success) was supported: career practitioners did believe that career image was important to career success, with interpersonal skills reported as the most important aspect, and beauty the least. Eye contact and the abilities to make conversation and to form relationships were the specific factors which were thought to have most impact.

Table 3provides an overview of the career practitioners' views on the importance of career image to career success. Practitioners were asked to rate on a 5-point Likert scale ( $1=$ not at all important, $2=$ slightly important, $3=$ somewhat important, $4=$ moderately important, $5=$ extremely important) how important they believed particular aspects of career image were to career success. Career practitioners' overall scores suggested that they felt that career image was somewhat important to career success. This overall score however obscured some variations, with practitioners reporting that interpersonal skills were moderately important, self-presentation somewhat important and beauty slightly important. The category of interpersonal skills comprised four factors: eye contact, the ability to form relationships, the ability to make conversation and accent. The mean scores for the first three were high but for accent the mean score was lower, perhaps because accent is not an appropriate measure of interpersonal skills. Were accent removed from the scale, the mean would be increased from $M=3.80$ to $M=4.12, S D=0.47$ revealing an even greater difference between the importance the practitioners placed on interpersonal skills versus beauty.

Table 3. Importance of Elements of Career Image to Career Success: Means and Standard Deviations

[table 3 near here]

More specifically, the factor which emerged as being the most important to the career practitioners was the ability to form relationships: they considered this to be extremely important to career success. Moreover, they considered eye contact, the ability to make conversation, wearing smart clothes and avoiding inappropriate piercings as moderately important to career success. All other factors were considered somewhat important with the exception of a good figure, an attractive face, and accent, which were considered slightly important.

A further independent-samples t-test was conducted to compare the 'how important?' scores for males and females on all different aspects of career image. For most of the factors there was no statistically significant difference between men and women. A significant difference in scores for males $(M=2.29, S D=0.97)$ and females $(M=2.0, S D=0.95), t(397)=2.77, p=0.021$ (Levene's test for 
equality of variance, $\mathrm{F}=1.52$, Sig .219), was found for how important they thought ' $a$ good figure' was to career success, with men believing that having a good figure was significantly more important to career success than women.

\section{Career practitioners do raise issues of appearance with clients}

$\mathrm{H} 2$ (Career practitioners discuss career image with their clients) was supported: practitioners are prepared to have conversations about career image with their clients. An overwhelming majority (96\%) of practitioners reported that the subject of appearance could come up in their professional conversations with $63 \%$ saying that they would raise the issue with clients, and $33 \%$ that they might. This finding was consistent across all demographic groups including professional role and client group.

Career practitioners were asked which particular features of career image they would be likely to raise in conversations with clients. The most common were eye contact, which might be raised by $98 \%$ of those who would or might have discussions about image; clothing, which might be raised by $95 \%$; and handshake, which might be raised by $82 \%$.

These responses were then compared to the number of career practitioners who reported that they felt each of the factors were important to career success (combined totals of those who rated it as 'moderately important', 'very important' or 'extremely important') to investigate H3 (career practitioners are more likely to have discussions about the elements of career image which they believe have most impact on career success). Analysis revealed that this hypothesis was not fully supported as the findings revealed that practitioners are not always keen to raise the topics which they feel have the most impact. These comparisons are illustrated in Figure 2. The factors which were rated as important by the highest number of participants (eye contact, handshake and clothing) were also those which they were most likely to discuss with clients. There was, however, a clear discrepancy between the value participants placed on hair, facial hair and weight, and their chances of raising these topics with clients. Weight, in particular was rated as important by $56 \%$ of participants, but would only be raised by $7 \%$.

Figure 1: A comparison between career image issues that career practitioners would raise and those that they think are important

\section{[Figure 1 near here]}

$\mathrm{n}=382$

NB In the survey, career practitioners were asked whether they would raise aspects of appearance which were considered relatively easy to alter.

\section{Career practitioners who engage with the topic feel somewhat well equipped to have these discussions, but would value further guidance.}

Overall, career practitioners who reported that they engage with the topic with clients (those who answered 'yes' or 'maybe' to the question 'Would you ever advise a client on how they looked to enhance their career prospects?') reported that they felt fairly comfortable when giving clients advice or feedback on how they look. Practitioners were asked to rate their comfort levels on a Likert scale from 1 (not at all comfortable) to 5 (extremely comfortable) and the mean score was $3.19(\mathrm{SD}=0.99)$, indicating that on average the group felt somewhat comfortable having 
conversations about career image. Practitioners reported that they felt well informed about the different kinds of clothes and appearance different employers were looking for ( $M=3.67, S D=1.07)$.

The majority of practitioners acknowledged that they would value further guidance, with three quarters (76\%) wanting more information about employers' expectations of appearance and behaviour, two thirds (66\%) requesting further ethical guidance on their role in this area, and over half (52\%) reporting that they would value further training in how to give advice to clients on these issues.

\section{Practitioners' levels of comfort in raising these issues with clients are associated with demographic factors (age and sex) and beliefs about career image (how well informed they feel about the issues and how confident they feel about their own career image).}

H4 (Career practitioners' levels of comfort in these discussions are associated with a range of factors including demographic factors and their beliefs about career image) was partially supported. Demographic data were gathered about a wide range of participant features, including ethnicity, religion, nationality, age, professional role and client group. Two ordinary least squares (OLS) regression analyses were conducted, the first to identify any associations between practitioner levels of comfort in raising these issues with clients and demographic factors of age, sex, role ethnicity, religion and client group. The demographic data were collected as categorical data so dummy variables were created to convert the categorical variables into nominal variables for the regression analysis. The second regression analysis sought to identify associations between practitioner levels of comfort, and practitioner beliefs about career image, specifically how important practitioners believe career image is to career success, how well informed they feel about the issues, and how confident they feel about their own career image. The results of these analyses are presented in Tables 4 and 5.

The demographic factors model explained $9 \%$ of the variance in levels of comfort with raising these issues with clients $(9 \%, F[16,355]=2.19, \mathrm{p}=0.005)$. The overall model fit was $\mathrm{R}$ squared 0.09 . Two variables emerged as significant predictors. The strongest predictor was age (Beta $=-0.169$, $p<0.003$ ), showing that participants in the younger groups (aged $18-30$ ) tended to have lower levels of comfort when raising issues of appearance and image with clients than older practitioners. The second demographic factor which was statistically significant within the model was sex (Beta = $0.117, p=0.026$ ) with female career practitioners tending to feel less comfortable than their male counterparts raising these issues with clients. Thus, younger $(18-30)$ and female practitioners were found to be less comfortable having conversations related to career image than other practitioners.

Table 4. Summary of OLS Regression Analysis for Variables Predicting Levels of Comfort Raising Issues of Appearance with Clients on Demographic Factors (age, sex, client groups, religion and ethnicity)

[Table 4 near here]

The second OLS regression was used to assess the association between how comfortable practitioners felt raising this issue and their beliefs about career image, specifically how important career image is to career success; how well informed practitioners feel about the different kinds of clothing / appearance employers are looking for; and how confident they feel about their own 
career image. This model explained $11.5 \%$ of the variance in levels of comfort with raising issues of career image with clients $(11.5 \%, F(3,378)=16.07, p<.001)$. The overall model fit was $\mathrm{R}$ squared 0.11 . How well informed practitioners felt about the issues received the strongest weight in the model (Beta $=0.23, p<0.001$ ), followed by practitioners' confidence in their own career image (Beta $=0.17, p=0.001)$. The degree to which participants felt that career image was important to career success was not a significant predictor (Beta $=0.045, p=n . s$.). Among career practitioners who responded to the survey, those who felt the most well informed about what employers are looking for in the appearance of their employees tended to feel the most comfortable discussing career image issues with clients. Those who felt positive about their own career image were also more likely to feel confident in their discussions about career image with clients.

Table 5. Summary of OLS Regression Analysis for Variables Predicting Levels of Comfort in Discussing Issues of Appearance with Clients on Beliefs about Career Image (how well informed participants feel, how confident they are in their own career image and how important they feel career image is to career success).

[Table 5 near here]

The correlations among the career practitioners' levels of comfort in discussing issues of appearance and their beliefs about career image were statistically significant and positive, although the strength of the correlations was weak. Correlations are presented in Table 6.

Table 6

Career practitioners' beliefs about career image: correlations

[Table 6 near here]

\section{Discussion}

This research raises some important issues which have implications for both professionals and researchers in the field. The results highlight that career practitioners acknowledge the importance of career image to some degree and that nearly all incorporate discussions about these topics in their career practice. Whilst practitioners reported that they felt relatively comfortable with, and well informed about the issues, other factors point to the need for further guidance and training in this sphere. The findings underscore some inconsistencies which are interesting to explore.

Amongst the practitioners who responded to the survey, there was an acknowledgement that issues of appearance and image do influence career success. However, in terms of two aspects of beauty (a beautiful face, and a good figure) and one of the five aspects of interpersonal skills (accent), the consensus was that these particular factors have more limited impact on career success than other aspects of image.

The literature does not provide us with a clear understanding of the relative importance of these factors, nor their impact on career success relative to other features such as personality, IQ or relevant experience. It is therefore difficult to comment on the validity of the practitioners' views overall. There are, however, some comparisons between the values placed on particular features which may be useful to highlight. The practitioners, for example, reported that they believed a firm 
handshake to have significantly more impact on career success than an individual's accent. Although a firm handshake has been found to influence recruiters' impressions of candidates (Stewart et al., 2008), there is a wealth of research which demonstrates the extensive impact that accent has on perceptions of personality, likeability, credibility, honesty, IQ, competence, employability and status, and evidence demonstrates that accent feeds into discrimination based on race, sexuality, ethnicity and class (see Carlson and McHenry, 2006, for a review). The breadth of the impact that accent has on perceptions and the comparative weight that the literature places on accent over handshake is at odds with the practitioners' view that accent is far less influential than handshake.

One possible explanation for this paradox could be gleaned from the value that career practitioners place on social justice. While there is relatively little research on the political and ontological perspectives of career practitioners, Arthur, Collins, McMahon and Marshall's (2009) work in Canada suggests that many careers professionals hold social justice as a key value although acknowledge that their definitions of the term vary. The unfairness inherent in accent-based discrimination may well be unpalatable to many career practitioners, and this may have an impact on their worldview. An alternative explanation could lie in the fact that this cognitive processing takes place below the level of consciousness (Campbell-Kibler, 2010; Chartrand \& Bargh, 1999). Practitioners may therefore not be aware of the extensive impact that accent has within society, nor indeed be fully cognisant of their own responses to accent. Further research is needed to identify the aspects of career image which have the most impact on career success in order to allow career workers to focus their energy where it is likely to be most productive and to highlight areas in which their assumptions may diverge from this.

A second paradox which emerged from the data relates to practitioners' views of how well informed they felt about the image and appearance that employers are looking for. The majority of career practitioners who responded to the survey (62\%) reported that they felt 'very' or 'extremely' well informed, yet $75 \%$ stated that they wanted more information about employers' expectations in this arena. Building up a comprehensive and in-depth understanding of the cultural mores related to career image in the workplace would be a Herculean task. We have highlighted Bourdieu's notion of 'habitus' in the literature review and discussed how these subtle, subconscious, nuanced, everchanging and implicit rules govern how to look and how to behave in any workplace. Given the vast number of industries, organisations and roles career practitioners address, it would, arguably, be impractical for practitioners to acquire more than a broad knowledge of the acceptable career image in a handful of organisational contexts. The challenge of developing the requisite knowledge is compounded by the weak evidential basis of many of the available resources. This is consistent with the finding that most practitioners feel the need for further information, but leaves a question over the large number of respondents who feel well informed. It would be interesting to explore in more depth why practitioners feel well informed about career image within employment contexts given its complexity and the lack of empirical information available.

The third incongruity revealed in the data is that whilst career practitioners generally reported that they would raise the topics which they feel have most impact on career success, there were significant exceptions to this. The most striking of these is weight, which was reported as an important factor by $56 \%$ of practitioners who responded to the survey, but would only be raised by $7 \%$. Differences too could be discerned in the number of practitioners who felt that facial hair and make-up were important to career success ( $70 \%$ and $68 \%$, respectively) and the proportion who would raise these topics with clients ( $41 \%$ and $50 \%$ respectively). The reasons behind these inconsistencies are likely to be complex. Some elements of career image are delicate, and career 
practitioners may feel that highlighting a client's perceived shortcomings might risk damage either to the client's self-esteem, or to the vital working alliance between practitioner and client (Heppner and Hendricks, 1995). Other aspects might be thought to be symbols of a client's social identity (Hogg and Terry, 2000), so could be considered by practitioners as inappropriate to raise. Pragmatics too may play a part, with practitioners perhaps preferring to open a discussion about a feature which is relatively easy for a client to change (such as a handshake) rather than to launch into a conversation about one which is more likely to be challenging (such as losing weight). Career practitioners reported that they would value further ethical guidelines in this field, and would welcome training in how to have productive conversations with clients about the issues. These two factors could contribute to an explanation for practitioners' reluctance to raise some topics they feel are important, as they may be unsure where the boundaries of their role should lie, or may feel illequipped to facilitate productive and positive discussions.

To explore possible explanations for career practitioners' levels of comfort when discussing these issues with client, we ran two OLS regression analyses to ascertain whether demographic characteristics of career practitioners or their beliefs about career image played a role. The regression models together accounted for just $20 \%$ of the variance in levels of comfort identified. There are clearly other factors at play. We have already highlighted that the sample was not representative. Career practitioners who responded to the survey were all self-selected, pointing perhaps to a population with an existing interest in these matters, many of whom will have undertaken similar or identical professional training programmes which may further homogenise the views of the population. The self-reported nature of the data and issues such as the social desirability of certain responses or practitioner confidence in their own competence too may have resulted in bias. Future research could examine other demographic variables such as class, political ideologies and personality types, as well as explore the nature of the conversations in more depth. Our future analysis of the qualitative data gathered as part of the same survey may also shed some light on these issues.

On top of these complexities in the data, the results suggest some broader questions about the role of career workers and the nature of their engagement with their clients, and with society at a broader level. The participants overwhelmingly (96\%) reported that issues of image are part of the career practitioners' remit, but what should we make of this?

Given the weight of evidence showing that career image matters, and given the impetus for career practitioners to support their clients in fulfilling their career aspirations, practitioners' engagement with the issues could be seen in a positive light. One could argue that engaging in potentially uncomfortable discussions shows a positive commitment to getting the best outcomes for their clients. Implications for practice could centre on how to encourage practitioners to focus on these matters more, and how to train them to understand the issues in more depth and to find the most effective interventions. This approach appears to be reflected to some degree in careers information. Career materials tend to avoid overt discussions of beauty but interpersonal skills and self-presentation are incorporated, and allusions to beauty can be found. Careers 2015 (Trotman, 2014), for example, suggests that beauty therapists should be of 'smart appearance' and fabricators should be 'fit'.

An alternative perspective might be to view the current level of practitioner engagement with career image as a source of concern. Career practitioners have a long and firm tradition of valuing and 
promoting social justice to the advantage of both society as a whole and their individual clients. The advantages that are conferred to those who are blessed with charm and good looks are unfair and place further barriers in the way of those who are already facing prejudice and discrimination in the workplace. One could argue that the choice to engage with these issues with individual clients is complicit support for an unjust status quo.

The quantitative data presented in this article leave a number of these questions open. The political orientation of discussions about career image cannot easily be inferred simply by the presence or absence of the dialogue. Rather it is necessary to examine in more depth the nature of conversations. A valuable line of enquiry could explore whether discussions about career image are qualified or contextualised politically and whether having a good career image is presented as an absolute good or a necessary evil by careers workers.

A limitation of the current research is that it has focused on the interaction between the client and the career practitioner. Career practice is broader than this and may include interactions with employers and a wide range of other stakeholders in the education system and the labour market. One question which remains unanswered is whether career practitioners are discussing issues of career image in these other places, for example, having conversations with employers to promote good practice in selection and recruitment. Further research into this aspect of career practice would also provide more insights into the way career image is handled by the profession.

The discussion so far has explored whether career practitioners have or even could develop the requisite knowledge to give clients useful advice on what to wear and how to behave in the workplace. There is, perhaps, a paradigmatic question which should be addressed first, namely, whether information-giving is the most effective role for career practitioners. Many career practitioners adhere, at least in theory, to a principle of non-directivity (Rogers, 1967). This is a philosophical position which puts a non-directive approach at the heart of any professional intervention. Much career practice literature (such as Ali and Graham, 1996; Egan, 1990) encourages practitioners to adopt this client-centred approach, allowing the client to set the agenda, identify their own solutions and decide on their own actions. Within this professional framework, practice does not hinge on imparting information, but professional expertise lies instead in the skills of facilitating clients to pinpoint the gaps in their knowledge, and supporting them to identify ways to close those gaps. Assuming this approach, career practitioners do not need to be equipped with an in depth knowledge of the habitus of each industry, organisation and role their clients are considering. Their practice focuses instead on encouraging clients to reflect on their own career image within the context of the particular opportunities they are considering, and to enable clients to identify any mismatch, and generate their own ideas for making changes, should they so choose. Professional discussions may centre on how and where the client could find the requisite information and the career worker may make use of a sophisticated understanding of the research process needed to identify a particular habitus which they may share with their client or use within an intervention to investigate collaboratively.

An alternative conceptualisation of career work positions the practitioner in more of an educational or mentoring role (Artaraz, 2006), providing advice and guidance based on knowledge, and imparting information. Such conceptions of career practice often emphasise the importance of labour market information as an objective foundation for interactions with clients. In this sense information about career image could be viewed as a specialised form of labour market information. This mentoring approach to career practice would require practitioners to be able to input information and resources which may aid an individual in their reflection about appropriate career image and support them to understand and decode the strategies which might lead to greater 
success (however this is determined). Such a position places greater demands on the practitioner to gather information and resources which can provide individuals with insights. It also opens the practitioner up to greater risks of getting it wrong. The level of knowledge about career image assumed by the career practitioners who responded to this survey is a boon to their clients as long as this knowledge is correct. If this knowledge is built on unreliable or outdated assumptions it has the potential to be dangerous.

Bimrose (2004) discussed a similar ethical and practical dilemma in her work on the related subject of sexual discrimination. She argues that practitioners need to work with girls and women to help them to recognise that their gender may result in them having different employment experiences from their male counterparts. The provision of information about actual labour market conditions can be empowering. In addition Bimrose highlights the need to operate on the demand side of the labour market and to seek to challenge structural inequalities through work with employers and other stakeholders. As we have already noted, this survey focused on career workers relationships with their clients and not with these wider stakeholders. This wider conception of career workers' roles is likely to be important in thinking about how the concept of career image can be operationalised into career practice in a way that supports social justice.

We have discussed the range of perspectives that career practitioners espouse, each with its own set of priorities and practices. These paradigmatic questions of the role of information in career practice and the distinction between a non-directive, person-centred, and an educational or mentoring approach are part of a broader debate about the theoretical and practical nature of career practice. As a consequence, practitioners informed by different traditions may resolve these issues in different ways.

Finally it is worth drawing attention to the homogeneity of the views captured. The survey results demonstrate a high degree of agreement between the career practitioners who responded to the survey. Whilst there are some demographic differences in the way that different groups of respondents address these issues, these are typically small and confined to a few issues of examples of practice. Concerns about the sampling of the participants have already been highlighted and further research is needed to explore this more thoroughly.

\section{Conclusion}

The results of this study clearly demonstrate that discussion of career image constitutes part of many career practitioners' professional practice. Yet, the inconsistencies highlighted in the findings, together with the explicitly stated development needs of the participants suggest that there is a need for additional evidence and guidance. This is, perhaps, unsurprising given the lack of theorisation of the issue of career image and the lack of any well-evidenced information sources that might inform the practice of careers workers.

Guidelines about the ethical and practical nature of the work would serve to increase the consistency of provision, and would ensure that interventions are effective. Specifically, we emphasise the need for research to deepen the level of understanding of the nature of the practice that is being reported here; the development of case studies which facilitate the sharing of expertise and underpin the development of future models of practice; and above all, the establishment of a discourse of ethics which allow career practitioners to think about how to square addressing career image with the wider ethical responsibilities of the role.

\section{References}


Agerstrom, J., \& Rooth, D. (2011). The role of automatic obesity stereotypes in real hiring discrimination. Journal of Applied Psychology, 96, 790-805

Ali, L. \& Graham, B. (1996). The Counselling Approach to Careers Guidance. Hove: Routledge

Artaraz, K. (2006). The wrong person for the job? Professional habitus and working cultures in Connexions Critical Social Policy, 26(4), 910-931.

Arthur, N., Collins, S., McMahon, M., \& Marshall, C. (2009). Career Practitioners' Views of Social Justice and Barriers for Practice. Canadian Journal of Career Development, 8(1), 22-31.

Behrens, J. T. (1997). Principles and procedures of exploratory data analysis. Psychological Methods, 2(2), 131-160.

Berger, E. D. (2009). Managing age discrimination: An examination of the techniques used when seeking employment. The Gerontologist, 49, 317-332.

Bimrose, J. (2004). Sexual harassment in the workplace: An ethical dilemma for career guidance practice? British Journal of Guidance and Counselling, 32(1), 109-121.

Bóo, F. L., Rossi, M. A., \& Urzua, S. S. (2013). The labor market return to an attractive face: Evidence from a field experiment. Economics Letters, 118(1), 170-172.

Burkhardt, J. C., Weider-Hatfield, D., \& Hocking, J. E. (1985). Eye contact on contrast effects in the employment interview. Communication Research Reports, 2(1), 5-10.

Campbell-Kibler, K. (2010). The sociolinguistic variant as a carrier of social meaning. Language Variation and Change, 22(3), 423-441.

Cargile. A. C. (2000). Evaluations of employment suitability: Does accent always matter? Journal of Employment Counseling, 37, 165-177.

Carlson, H.K. \& McHenry, M.A. (2008). Effect of accent and dialect on employability. Journal of Employment Counseling, 43, $70-83$.

Cavico, F. J., Muffler, S. C., \& Mujtaba, B. G. (2012). Appearance discrimination, "lookism" and "lookphobia" in the workplace. Journal of Applied Business Research (JABR), 28(5), 791-802.

Chartrand, T.L. \& Bargh, J.A. (1999). The chameleon effect: the perception - behavior link and social interaction. Journal of Personality and Social Psychology, 76(6), 893-910

Cutts, B., Hooley, T. \& Yates, J. (2015). Graduate dress code: How undergraduates are planning to use hair, clothes and make-up to smooth their transition to the workplace. Industry and Higher Education. 29(4):271-282.

Egan, G. (1990). The Skilled Helper. California: Brooks/Cole Publishing Company

Eustace, E. (2012). Speaking allowed? Workplace regulation of regional dialect. Work, Employment and Society, 26(2), $331-348$.

Grant, B. (2004) The imperative of ethical justification is psychotherapy: The special case of clientcentred therapy. Person-centred and Experiential Psychotherapies, 3, 152-165

Greene, D. W. (2011). Black women can't have blonde hair... in the workplace. Journal of Gender, Race and Justice, 14(2), 405-431. 
Hall, R., \& van den Broek, D. (2012). Aestheticising retail workers: Orientations of aesthetic labour in Australian fashion retail. Economic and Industrial Democracy, 33 (1), 85-102.

Hazen, L., \& Syrdhal, J. (2010). Dress codes and appearance policies: What not to wear at work. The Colorado Lawyer, 39, 55-63.

Heppner, M.J. \& Hendricks, F. (1995). A process and outcome study examining career indecision and indecisiveness Journal of Counseling and Development, 73, 426- 437.

Hogg, M. A. \&Terry, D.J. (2000). Social identity and self-categorization processes in organizational contexts. Academy of Management Review, 25(1) 121-140.

Hooley, T., Marriott, J., \& Wellens, J. (2012). What Is Online Research? Using the Internet for Social Science Research. London: Bloomsbury.

Hooley, T. and Yates, J. (2015) If you look the part you'll get the job British Journal of Guidance and Counselling, 43(4), $438-451$.

Howlett, N., Pine, K.J., Cahill, N., Orakcioglu, I. \& Fletcher, B. (2015) Unbuttoned: The interaction between provocativeness of female work attire and occupational status. Sex Roles, 72(3-4), 105116.

Hübler, O. (2009). The nonlinear link between height and wages in Germany, 1985-2004. Economics and Human Biology, 7, 191-199.

Huffcutt, A. I., Conway, J. M., Roth, P. L., \& Stone, N. J. (2001). Identification and meta-analytic assessment of psychological constructs measured in employment interviews. Journal of Applied Psychology, 86, 897-913

IAEVG. (2014). Statement on social justice. Retrieved from http://www.iaevg.org/iaevg/nav.cfm? lang $=2 \&$ menu $=1 \&$ submenu=9 [Accessed $21^{\text {st }}$ June 2015].

Jæger, M. (2011). "A thing of beauty is a joy forever?" Returns to physical attractiveness over the life course. Social Forces, 89, 983-1003.

Judge, T. A., \& Cable, D. M. (2011). When it comes to pay, do the thin win? The effect of weight on pay for men and women. Journal of Applied Psychology, 96, 95-112.

Karl, K. A., Hall, L. M., \& Peluchette, J. V. (2013). City employee perceptions of the impact of dress and appearance: You are what you wear. Public Personnel Management, 42(3), 452-470.

Madera, J. M., \& Hebi, M. R. (2012). Discrimination against facially stigmatized applicants in interviews: An eye-tracking and face-to-face investigation. Journal of Applied Psychology, 97, 317-330.

Ng, T.W.H., Eby, L.T., Sorensen, K.L. and Feldman, D.C. (2005) Predictors of objective and subjective career success: a meta-analysis. Personnel Psychology 58(2), $367-408$.

Parmentier, M., Fischer, E. \& Reuber, A.R. (2013). Positioning person brands in established organizational fields. Journal of the Academy of Marketing Science, 41, 373-387.

Resenhoeft, A., Villa, J. \& Wiseman, D. (2008). Tattoos can harm perceptions: a study and suggestions Journal of American College Health, 56, 593-596. 
Rogers, C. R. (1967). The necessary and sufficient conditions of therapeutic personality change. Journal of Consulting and Clinical Psychology 21, $95-103$.

Ruetzler, T., Taylor, J., Reynolds, D. \& Baker, W. (2011). Understanding perceptions of professional attributes using conjoint analysis International Journal of Hospitality Management, 30 (3), 551-557.

Sheane, S. D. (2012). Putting on a good face: An examination of the emotional and aesthetic roots of presentational labour. Economic and Industrial Democracy, 33(1), 145-158.

Stewart, G. L., Dustin, S. L., Barrick, M. R., \& Darnold, T. C. (2008). Exploring the handshake in employment interviews. Journal of Applied Psychology, 93, 1139-1146.

Trotman (2014) Careers 2015 Bath: Trotman Education

Ustuner, T. \& Thompson, C. (2012). How marketplace performances produce interdependent status games and contested forms of symbolic capital. Journal of Consumer Research, 38, 796-814.

Warhurst, C. \& Nickson D. (2007) Employee experience of aesthetic labour in retail and hospitality Work, employment and society 21(1) $103-120$ 
Table 1

\begin{tabular}{lr|lr|lr|lr}
\begin{tabular}{ll|ll|l} 
Age \\
Range
\end{tabular} & $\%$ & Ethnicity & $\%$ & Religion & $\%$ & $\begin{array}{l}\text { Country of } \\
\text { residence }\end{array}$ & $\%$ \\
\hline $18-25$ & 2 & White & 89 & Christian & 43 & England & 67 \\
$26-30$ & 5 & 3 & $\begin{array}{l}\text { No religion / } \\
\text { humanist }\end{array}$ & 39 & Scotland & 5 \\
$31-40$ & 26 & $\begin{array}{l}\text { Spiritual } \\
\text { Cack / Africa / }\end{array}$ & 2 & 2 & N. Ireland & 1.5 \\
$41-50$ & 28 & $\begin{array}{l}\text { Mixed ethnic } \\
\text { groups }\end{array}$ & 2 & Jewish & 2 & Wales & 0.5 \\
$51-60$ & 34 & $\begin{array}{l}\text { Prefer not to } \\
\text { say }\end{array}$ & 4 & Other religions & 5 & Rest of Europe & 9 \\
$70+$ & 4 & 1 & & Prefer not to say & 8 & Rest of the World & 10 \\
\hline
\end{tabular}

Table 2

\begin{tabular}{|c|c|c|c|}
\hline Client Group & $\%$ & Role & $\%$ \\
\hline University students & 30 & $\begin{array}{l}\text { Careers adviser / counsellor / } \\
\text { coach }\end{array}$ & 64 \\
\hline Young people in schools & 20 & Manager & 20 \\
\hline Working adults & 18 & Teacher / lecturer & 5 \\
\hline College students & 11 & Reception / support role & 1 \\
\hline Unemployed adults & 10 & Prefer not to say & 10 \\
\hline $\begin{array}{l}\text { Young people not in } \\
\text { education employment or } \\
\text { training }\end{array}$ & 5 & & \\
\hline Prefer not to say & 6 & & \\
\hline
\end{tabular}

Table 3

\begin{tabular}{lll} 
Elements of Career Image & Mean & Standard Deviation \\
\hline & & \\
Ability to form relationships & 4.55 & 0.57 \\
Eye contact & 4.45 & 0.60 \\
Ability to make conversation & 4.31 & 0.68 \\
Accent & 2.29 & 0.92 \\
Total Interpersonal Skills & $\mathbf{3 . 8}$ & $\mathbf{0 . 4 6}$ \\
\hline Wearing smart clothes & 3.78 & 0.76
\end{tabular}




\begin{tabular}{lll} 
Avoiding inappropriate piercings & 3.51 & 1.04 \\
Firm handshake & 3.4 & 0.88 \\
Avoiding visible tattoos & 3.31 & 1.05 \\
Well styled hair & 3.21 & 0.9 \\
Appropriate facial hair & 3.01 & 1.03 \\
Appropriate make-up & 3.05 & 1.05 \\
Appropriate jewellery & 2.98 & 1.06 \\
Total self-presentation & $\mathbf{3 . 2 8}$ & $\mathbf{0 . 7 6}$ \\
\hline A healthy weight & 2.62 & 0.96 \\
Attractive face & 2.28 & 0.97 \\
A good figure & 2.12 & 0.96 \\
Total Beauty & $\mathbf{2 . 3 3}$ & $\mathbf{0 . 8 6}$ \\
\hline Total Career Image & $\mathbf{3 . 2 6}$ & $\mathbf{0 . 5 3}$ \\
\hline
\end{tabular}

$\mathrm{N}=399$

Table 4

\begin{tabular}{|c|c|c|c|}
\hline & $\mathrm{B}$ & SEB & Beta \\
\hline \multicolumn{4}{|l|}{ Demographic Variables } \\
\hline \multicolumn{4}{|l|}{ Age } \\
\hline $18-30$ & -.623 & .205 & $-.169 * *$ \\
\hline $31-40$ & -.218 & .137 & -.097 \\
\hline $41-50$ & -.046 & .135 & -.021 \\
\hline $51-60$ & .072 & .147 & .011 \\
\hline $61+$ & .145 & .252 & .032 \\
\hline \multicolumn{4}{|l|}{ Sex } \\
\hline Female & -.264 & .118 & $-.117^{*}$ \\
\hline \multicolumn{4}{|l|}{ Client Group } \\
\hline NEETs & .005 & .316 & .001 \\
\hline College Student & .099 & .244 & -.032 \\
\hline Young People in Schools & .054 & .229 & .022 \\
\hline Working Adults & -.299 & .234 & -.115 \\
\hline University Students & -.032 & .218 & -.015 \\
\hline Unemployed Adults & -.046 & .259 & -.014 \\
\hline \multicolumn{4}{|l|}{ Religion } \\
\hline No Religion & -.107 & .215 & -125 \\
\hline Other Religions & -.451 & .278 & -.125 \\
\hline Christian & -.018 & .213 & -.009 \\
\hline \multicolumn{4}{|l|}{ Ethnicity } \\
\hline White British & -.363 & .192 & -.105 \\
\hline Other ethnicity & .301 & .194 & .087 \\
\hline \multicolumn{4}{|l|}{ Country } \\
\hline England & -.125 & .124 & -.54 \\
\hline Rest of the World & .140 & .124 & .061 \\
\hline \multicolumn{4}{|l|}{ Role } \\
\hline Manager & -.175 & .211 & -.072 \\
\hline $\begin{array}{l}\text { Careers adviser / coach/ } \\
\text { counsellor }\end{array}$ & -.192 & .188 & -.093 \\
\hline
\end{tabular}


Teacher / Lecturer

${ }^{*} \mathrm{p}$ value $<.05,{ }^{* *} \mathrm{p}$ value $<.01$

$\mathrm{N}=382$

Table 5

\begin{tabular}{llll}
\hline & B & SEB & Beta \\
\hline Belief Variables & & & \\
\hline $\begin{array}{l}\text { How important is career } \\
\text { image to career success? }\end{array}$ & .084 & .096 & .045 \\
$\begin{array}{l}\text { How well informed do you } \\
\text { feel about career image? }\end{array}$ & .15 & .049 & $.227^{* *}$ \\
$\begin{array}{l}\text { How confident do you feel } \\
\text { about your own career } \\
\text { image? }\end{array}$ & .118 & .096 & $.17^{*}$ \\
\hline \hline
\end{tabular}

${ }^{* p}$ value $<.05,{ }^{* *} p$ value $<.01$

$\mathrm{N}=382$

Table 6

\begin{tabular}{|c|c|c|c|c|}
\hline Variables & 1 & 2 & 3 & 4 \\
\hline $\begin{array}{l}\text { 1. How confident are you } \\
\text { in your career image? }\end{array}$ & 1 & & & \\
\hline $\begin{array}{l}\text { 2. How well informed do } \\
\text { you feel about career } \\
\text { image? }\end{array}$ & $.293^{* *}$ & 1 & & \\
\hline $\begin{array}{l}\text { 3. How important do you } \\
\text { believe career image is to } \\
\text { career success? }\end{array}$ & $.270^{* \star}$ & $.219^{\star \star}$ & 1 & \\
\hline $\begin{array}{l}\text { 4. How comfortable do } \\
\text { you feel raising these } \\
\text { issues with clients? }\end{array}$ & $.240^{\star *}$ & $.284^{* *}$ & $.157^{* *}$ & 1 \\
\hline
\end{tabular}


